\title{
Serum Adipocyte Fatty Acid Binding Protein Levels in Patients with Type 2 Diabetes Mellitus and Obesity: the Influence of Fenofibrate Treatment
}

\author{
M. M. HALUZÍK ${ }^{1,3}$, K. ANDERLOVÁ ${ }^{1}$, R. DOLEŽALOVÁ ${ }^{1}$ A. ADAMÍKOVÁ \\ D. HALUZÍKOVÁ ${ }^{1,2}$, J. HOUSOVÁ ${ }^{1}, \breve{S}^{\text {. SVAČINA }}{ }^{1}$, M. HALUZÍK ${ }^{1}$
}

${ }^{1}$ Third Department of Medicine, ${ }^{2}$ Department of Sports Medicine, First Faculty of Medicine, Charles University and General University Hospital, Prague, ${ }^{3}$ Department of Chemistry, University of Ostrava, Ostrava and ${ }^{4}$ Diabetes Center, Bata Regional Hospital, Zlín, Czech Republic

Received August 8, 2007

Accepted November 28, 2007

On-line January 17, 2008

\section{Summary}

Recent studies have demonstrated that adipocyte fatty acid binding proteins (FABP) may play a role in the etiopathogenesis of insulin resistance. The aim of our study was to assess serum FABP levels in obese patients with type 2 diabetes mellitus (T2DM) before and after 3 months of treatment with PPAR- $\alpha$ agonist fenofibrate $(F)$ and to explore the relationship of FABP to biochemical parameters and measures of insulin sensitivity assessed by hyperinsulinemic-isoglycemic clamp. We measured biochemical parameters by standard laboratory methods, insulin sensitivity by hyperinsulinemic-isoglycemic clamp and serum concentrations of FABP by commercial ELISA kit in 11 obese females with T2DM before and after three months of treatment with PPAR- $\alpha$ agonist fenofibrate and in 10 lean healthy control women (C). Serum FABP levels were 2.5-fold higher in T2DM group relative to $\mathrm{C}$ and were not affected by fenofibrate treatment (C: $20.6 \pm 2.1 \mu \mathrm{g} / \mathrm{l}, \mathrm{T} 2 \mathrm{DM}$ before F: $55.6 \pm 5.7 \mu \mathrm{g} / \mathrm{l}$, T2DM after F: $54.2 \pm 5.4 \mu \mathrm{g} / \mathrm{l}, \mathrm{p}<0.0001$ for $C$ vs. T2DM before $F$ ). Hyperinsulinemia during the clamp significantly suppressed $F A B P$ levels in both $\mathrm{C}$ and T2DM group. FABP levels positively correlated with BMI, triglyceride levels, blood glucose, glycated hemoglobin, atherogenic index and insulin levels. An inverse relationship was found between FABP and HDL levels, metabolic clearance rate of glucose, $\mathrm{M} / \mathrm{I}$ and $\mathrm{MCR}_{\mathrm{gl}} / \mathrm{I}$ sensitivity indexes. We conclude that FABP levels are closely related to BMI, parameters of insulin sensitivity, HDL levels and measures of diabetes compensation. This combination makes FABP a valuable marker of metabolic disturbances in patients with type 2 diabetes mellitus.

\section{Key words}

FABP • Insulin sensitivity • Diabetes • Obesity • Glucose clamp

\section{Corresponding author}

M. Haluzík, Third Department of Medicine, First Faculty of Medicine, Charles University, U Nemocnice 1, 12808 Prague 2, Czech Rrepublic. E-mail: mhalu@1lf.cuni.cz

\section{Introduction}

The close interconnection between obesity/ insulin resistance, type 2 diabetes, dyslipidemia and several other pathologies within the so-called insulin resistance syndrome has been documented in numerous clinical studies (Reaven 1988, 1992). The combination of these pathologies represents a major risk factor for the development of accelerated atherosclerosis and its complications (Haffner 2003, Haffner et al. 1998). Insulin resistance is now considered a primary perturbation that in turn leads to other abnormalities (Shulman 2000). One of the possible etiopathogenetic mechanisms leading to development of insulin resistance and possibly directly contributing to the development of atherosclerosis is disturbed endocrine function of adipose tissue commonly present in patients with obesity and/or type 2 diabetes mellitus (Haluzík et al. 2004, Havel 2002, Housa et al. 2006, Housová et al. 2005).

Cytoplasmic fatty acid binding proteins (FAPBs) are a family of proteins expressed in various tissues including fat, that play an important role not 
only in lipid metabolism and other metabolic regulations (Boord et al. 2002). Recent clinical studies have shown that FABP4 produced primarily by adipocytes is released into the circulation suggesting its possible systemic effects (Karpíšek et al. 2007, Stejskal and Karpíšek 2006, Xu et al. 2006, 2007). It has been demonstrated that FABP concentrations are increased in patients with obesity and/or metabolic syndrome and may represent a novel marker of this clinical entity (Karpíšek et al. 2007, Stejskal and Karpíšek 2006, Xu et al. 2006). However, there are virtually no studies focused on direct relationship of FABP to insulin sensitivity and diabetes compensation. Here we examined the influence of well-known modulator of lipid metabolism PPAR- $\alpha$ agonist fenofibrate (GuerreMillo et al. 2000, Haluzík and Haluzík 2006, Haluzík et al. 2006, Staels et al. 1998, Yong et al. 1999) on circulating levels of FABP in patients with obesity and type 2 diabetes mellitus. We hypothesized that some of metabolic effects of fibrates may be mediated by changes of circulating FABP levels. We demonstrate that FABP circulating levels closely correlate with anthropometric measures of obesity, parameters of insulin sensitivity and with measures of diabetes compensation, but they are not affected by fenofibrate treatment.

\section{Methods}

\section{Study subjects}

Eleven obese females with type 2 diabetes mellitus and serum triglyceride concentrations above $2.0 \mathrm{mmol} / 1$ and 10 age-matched healthy normal-weight control women were included into the study. Their body weight remained stable for at least three months before the beginning of the study. The patients were treated with diet, metformin alone or combination of metformin and glimepiride. The diabetic medication remained unchanged from three months before the start throughout entire study. None of the studied subjects suffered from acute infectious disease. Written informed consent was provided by all participants before being enrolled in the study. The study was approved by the Human Ethical Review Committee, First Faculty of Medicine and General University Hospital, Prague, Czech Republic.

\section{Study protocol}

Measurements of clinical and hormonal parameters in type 2 diabetes patients were performed at baseline and after 3 months of treatment with PPAR- $\alpha$ agonist - fenofibrate (200 mg, Lipanthyl 267M). Control subjects were examined only once and did not receive any treatment.

\section{Anthropometric examination and blood sampling}

All subjects were measured and weighed, body mass index was calculated and blood samples were withdrawn after an overnight fasting. Serum was obtained by centrifugation and stored in aliquots at $-70{ }^{\circ} \mathrm{C}$ until further analysis.

\section{Hormonal and biochemical assays}

Biochemical parameters were measured by standard laboratory methods in the Department of Biochemistry of the General University Hospital. Serum insulin concentrations were measured by commercial RIA kit (Cis Bio International, France). Serum FABP concentrations were measured by commercial ELISA kit (BioVendor, Brno, Czech Republic).

\section{Hyperinsulinemic-isoglycemic clamp}

Hyperinsulinemic-isoglycemic clamp is based on the principle established by De Fronzo et al. (1979). Insulin efficiency is evaluated as the amount of glucose necessary to maintain the desired glucose levels under conditions of constant insulin infusion calculated per unit of body weight or body surface. In case of isoglycemic clamp the desired glucose level equals fasting blood glucose level.

At the beginning of the study two cannulas were inserted into forearm veins on both arms. One of the cannulas was used to infuse insulin solution (20 IU HM-R insulin in $20 \mathrm{ml} 0.9 \%$ saline solution, infusion rate: $1 \mathrm{mIU} / \mathrm{kg} / \mathrm{min}$ for patients with $\mathrm{BMI}<30 \mathrm{~kg} / \mathrm{m}^{2}$, $40 \mathrm{mIU} / \mathrm{m}^{2} / \mathrm{min}$ for patients with BMI $>30 \mathrm{~kg} / \mathrm{m}^{2}$ ) and glucose solution $(20 \%$ glucose solution $)+20 \mathrm{ml} 7.5 \%$ $\mathrm{KCl}$ in $500 \mathrm{ml} 0.9 \%$ sodium saline solution. Glucose infusion rate was modified according to changes of blood glucose concentration). The second cannula in the contralateral forearm was used for blood sampling for blood glucose in 5-min intervals and insulin measurements at baseline and steady-state period. Blood glucose concentration was measured by glucometer (Super Glucocard II, Arkray, Japan). Glucose clamp was finished after $3 \mathrm{~h}$ when "steady-state" i.e. period of stable blood glucose concentration close or equal to the desired value was reached for at least $30 \mathrm{~min}$. 
Table 1. Anthropometric, biochemical and hormonal parameters and measures of insulin sensitivity measured by hyperinsulinemicisoglycemic clamp in control group of healthy women and obese women with type 2 diabetes mellitus before (Obese 1) and after three months of treatment with PPAR- $\alpha$ agonist - fenofibrate (Obese 2).

\begin{tabular}{|c|c|c|c|}
\hline & Control group & Obese 1 & Obese 2 \\
\hline$B M I\left(\mathrm{~kg} / \mathrm{m}^{2}\right)$ & $23.7 \pm 0.8$ & $36.7 \pm 2.9 *$ & $36.5 \pm 2.7 *$ \\
\hline Insulin $(\mu I U / m l)$ & $23.0 \pm 2.9$ & $44.2 \pm 7.1 *$ & $47.5 \pm 8.0 *$ \\
\hline Cholesterol (mmol/l) & $5.39 \pm 0.24$ & $5.22 \pm 0.32$ & $5.09 \pm 0.25$ \\
\hline HDL-cholesterol (mmol/l) & $1.55 \pm 0.28$ & $1.17 \pm 0.11^{*}$ & $1.20 \pm 0.11^{*}$ \\
\hline LDL-cholesterol (mmol/l) & $3.01 \pm 0.15$ & $2.74 \pm 0.29$ & $2.90 \pm 0.19$ \\
\hline Triacylglycerol (mmol/l) & $0.98 \pm 0.12$ & $2.96 \pm 0.39 *$ & $2.17 \pm 0.24 * \circ$ \\
\hline Atherogenic index & $1.88 \pm 0.09$ & $3.17 \pm 0.37 *$ & $3.02 \pm 0.75^{*}$ \\
\hline Blood glucose $(\mathrm{mmol} / \mathrm{l})$ & $4.97 \pm 0.19$ & $8.48 \pm 0.68 *$ & $9.43 \pm 0.84 * \circ$ \\
\hline Glycated hemoglobin (\%) & $3.81 \pm 0.08$ & $5.77 \pm 0.56^{*}$ & $6.10 \pm 0.58 * \circ$ \\
\hline$M C R_{g l c}\left(m l . \mathrm{kg}^{-1} \cdot \mathrm{min}^{-1}\right)$ & $8.41 \pm 0.66$ & $2.70 \pm 0.44 *$ & $2.74 \pm 0.61 *$ \\
\hline$M / I\left(m g \cdot \mathrm{kg}^{-1} \cdot \min ^{-1}\right.$ per $\left.m I U \cdot m l^{-1}\right)$ & $0.062 \pm 0.008$ & $0.030 \pm 0.005^{*}$ & $0.026 \pm 0.0006^{*}$ \\
\hline$M C R_{g l c} / I\left(m l . \mathrm{kg}^{-1} \cdot \mathrm{min}^{-1}\right.$ per $\left.m I U \cdot \mathrm{ml}^{-1}\right)$ & $0.076 \pm 0.011$ & $0.021 \pm 0.003 *$ & $0.017 \pm 0.004^{*}$ \\
\hline
\end{tabular}

Values are means \pm S.E.M. Statistical significance is from one-way ANOVA and Paired t-test respectively. $* p<0.05$ vs. control group, ${ }^{\circ} \mathrm{p}<0.05$ obese group 1 vs. obese group 2. $M C R_{g / c}-$ metabolic clearence rate of glucose, $M / I, M C R_{g / d} I$ - insulin sensitivity indexes

The following parameters were calculated based on clamp results: glucose disposal rate $\left(\mathrm{M}, \mathrm{mg} \cdot \mathrm{kg}^{-1} \cdot \mathrm{min}^{-1}\right)$ was defined as the amount of glucose supplied by the infusion to maintain the desired blood glucose, glucose disposal rate $\left(\mathrm{M}_{\mathrm{korig}}, \mathrm{mg} \cdot \mathrm{kg}^{-1} \cdot \mathrm{min}^{-1}\right)$ corrected to urine glucose loss, metabolic clearance rate of glucose $\left(\mathrm{MCR}_{\mathrm{glc}}, \mathrm{ml} \cdot \mathrm{kg}^{-1} \cdot \mathrm{min}^{-1}\right)$ was expressed as the ratio of glucose disposal rate to blood glucose concentration and the insulin sensitivity indexes $\left(\mathrm{M} / \mathrm{I}\right.$ and $\mathrm{MCR}_{\mathrm{glc}} / \mathrm{I}$, mg.kg ${ }^{-1} \cdot \min ^{-1}$ per mIU.ml ${ }^{-1}, \mathrm{ml}^{-\mathrm{kg}^{-1}} \cdot \min ^{-1}$ per mIU.ml ${ }^{-1}$ ) were defined as the ratio of $\mathrm{M}$ or $\mathrm{MCR}_{\mathrm{glc}}$ and the average insulin concentration during the observed period (steadystate), respectively.

\section{Statistical analysis}

The statistical analysis was performed on SigmaStat software (Jandel Scientific, USA). The results are expressed as means \pm S.E.M. Data of T2DM women before and after treatment with fenofibrate were compared by paired t-test. Data of T2DM women vs. control subjects were compared by one-way analysis of variance followed by Dunnet's test. The changes of FABP during the clamp were analyzed by one way repeated measures analysis of variance followed by Holm-Sidak test. The relationship between variables were analyzed by Pearson or Spearman correlation test as appropriate.

\section{Results}

The influence of fenofibrate on anthropometric and biochemical parameters

At baseline, body mass index, serum glucose, triglyceride, insulin, glycated hemoglobin levels and atherogenic index in T2DM group were significantly higher (Table 1), while serum HDL cholesterol concentrations were significantly lower than in control group (Table 1). Three months of treatment with fenofibrate led to a significant decrease of serum triglyceride concentrations (Table 1), while both blood glucose and glycated hemoglobin significantly increased (Table 1). Other parameters including BMI were not affected by fenofibrate treatment (Table 1).

\section{The influence of fenofibrate on insulin sensitivity}

At baseline, all parameters of insulin sensitivity as measured by hyperinsulinemic-isoglycemic clamp were significantly lower in T2DM relative to control group suggesting blunted rate of glucose disappearance from circulation in response to infused insulin (Table 1). Three months of fenofibrate treatment did not significantly affect any of these parameters $\left(\mathrm{M}, \mathrm{M}_{\text {korig, }}\right.$, $\mathrm{MCR}_{\mathrm{glc}}, \mathrm{M} / \mathrm{I}, \mathrm{MCR}_{\mathrm{glc}} \mathrm{I}$ ) (Table 1). All parameters of insulin sensitivity remained significantly lower in T2DM relative to control group after three months of treatment with fenofibrate (Table 1). 

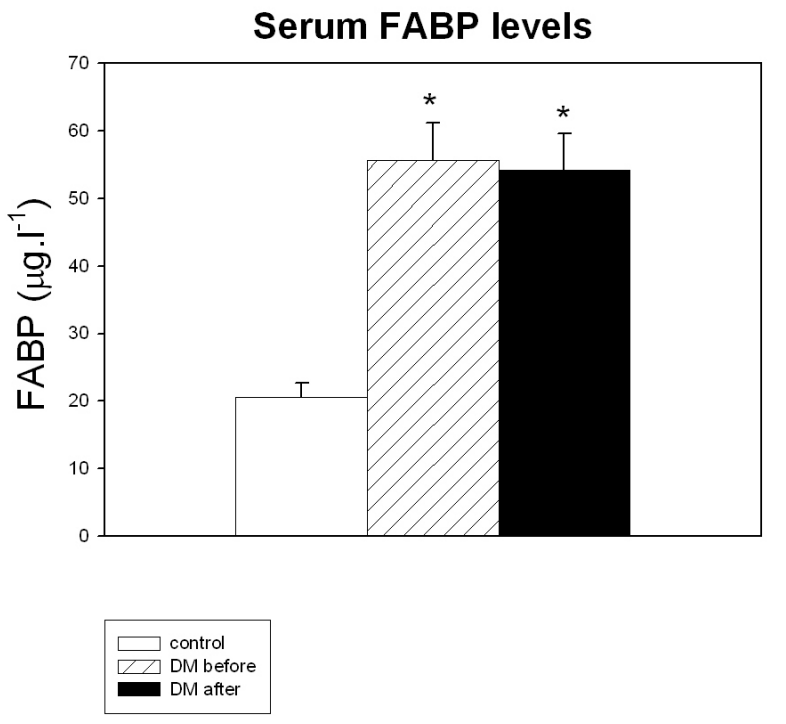

Fig. 1. Fasting serum FABP concentrations in control group (open bar), type 2 DM group before (dashed bar) and after three months of fenofibrate treatment (filled bar). Values are mean \pm S.E.M. Statistical significance is from one-way ANOVA and paired T-test: * indicates $p<0.05$ versus control group.

The influence of metabolic status, fenofibrate treatment and hyperinsulinemia during clamp on FABP levels

Fasting serum FABP concentrations in T2DM group before treatment with fenofibrate were more than two-fold higher than in control group $(\mathrm{p}<0.001)$ and 3 months of fenofibrate treatment did not affect this parameter (Fig. 1).

Ninety minutes of hyperinsulinemia during the clamp tended to decrease FABP levels in control group (non-significant change vs. baseline values) (Fig. 2). $180 \mathrm{~min}$ of hyperinsulinemia led to $16 \%$ decrease of FABP levels ( $p=0.03$ vs. baseline levels) (Fig. 2).

In type T2DM patients before fenofibrate treatment, $90 \mathrm{~min}$ of hyperinsulinemia during the clamp decreased FABP levels by $20 \%(p=0.025)$ (Fig. 2). $180 \mathrm{~min}$ of hyperinsulinemia in T2DM patients before fenofibrate treatment decreased serum FABP levels by $26 \% \quad(p=0.017$ vs. baseline values) (Fig. 2). The percentage of decrease in FABP levels in T2DM group during the clamp before fenofibrate treatment in both 90th and 180th min was significantly greater than in control group ( $\mathrm{p}=0.03$ and 0.009 , respectively).

In T2DM patients after 3 months of fenofibrate treatment, $90 \mathrm{~min}$ of hyperinsulinemia during the clamp decreased FABP levels by $7 \%$ (non-significant difference vs. baseline values) (Fig. 2). $180 \mathrm{~min}$ of hyperinsulinemia in T2DM patients after 3 months of fenofibrate treatment decreased serum FABP levels by $16 \%$ ( $p=0.036$ vs. baseline values). The percentage of
Serum FABP levels during isoglycemic-hyperinsulineı clamp

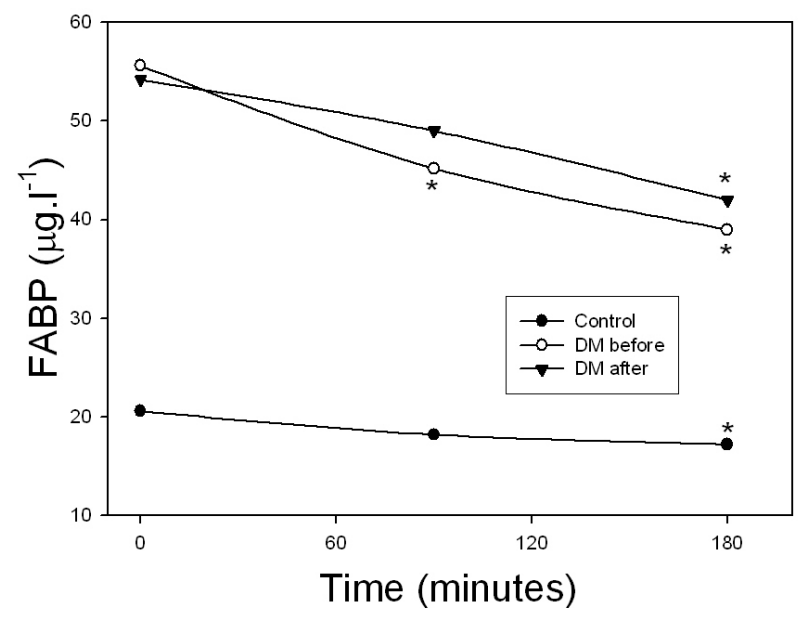

Fig. 2. Changes of FABP concentrations during isoglycemichyperinsulinemic clamp of control group of healthy women (filled circles), obese women with type 2 DM before (open circles) and after three months of treatment with PPAR- $\alpha$ agonist fenofibrate (filled triangles). Statistical significance is from RM ANOVA $* p<0.05$ vs. baseline value of the respective group.

decrease in FABP levels during the clamp in T2DM group after 3 months of fenofibrate treatment did not significantly differ from control group any more.

Relationship of serum FABP levels to anthropometric, biochemical and insulin sensitivity parameters

Due to a relatively low number of subjects the relationship of serum FABP levels to anthropometric, biochemical and insulin sensitivity parameters was analyzed in a combined group of healthy controls and T2DM patients before the treatment of fenofibrate. Serum FABP levels positively correlated with BMI $(r=0.80$, $\mathrm{p}<0.001)$, triglyceride levels $(\mathrm{r}=0.74, \mathrm{p}<0.001)$, blood glucose $(\mathrm{r}=0.83, \mathrm{p}<0.001)$, glycated hemoglobin $(\mathrm{r}=0.70, \mathrm{p}<0.001)$, atherogenic index $(\mathrm{r}=0.80, \mathrm{p}<0.001)$ and insulin levels $(r=0.50, p=0.04)$. An inverse relationship was found between FABP and HDL levels $(\mathrm{r}=-0.70, \mathrm{p}<0.001), \mathrm{FABP}$ and glucose disposal rate $(\mathrm{r}=-0.67, \mathrm{p}=0.002), \mathrm{FABP}$ and glucose disposal rate corrected to urine glucose loss $(r=-0.60, p=0.0087)$, FABP and metabolic clearance rate of glucose $(\mathrm{r}=-0.77$, $\mathrm{p}<0.001), \quad \mathrm{FABP}$ and $\mathrm{M} / \mathrm{I}$ insulin sensitivity index $(\mathrm{r}=-0.73, \mathrm{p}<0.001)$ and $\mathrm{FABP}$ and $\mathrm{MCR}_{\mathrm{glc}} / \mathrm{I}$ insulin sensitivity index $(r=-0.79, p<0.001)$, respectively.

\section{Discussion}

The most important finding of this study is the fact that circulating levels of FABP are strongly 
positively linked to BMI, blood glucose and glycated hemoglobin levels in patients with type 2 diabetes mellitus and have an inverse relationship to the parameters of insulin sensitivity measured by hyperinsulinemic-isoglycemic clamp. FABP thus may represent a novel and a very strong link between disturbed secretory function of adipose tissue and other metabolic abnormalities coupled within insulin resistance syndrome.

It has been previously documented in experimental studies that FABPs have an important role in shuttling of fatty acids to cellular compartments, modulation of intracellular lipid metabolism and regulation of gene expression (Binas et al. 1999, Levy et al. 2001, Wolfrum et al. 2001). For example, intestinal FABP is an important modulator of fatty acid absorption and chylomicron expression (Levy et al. 2001), while heart and liver FABPs are important players in fatty acid oxidation and fatty acid ligand signaling in the liver (Binas et al. 1999, Wolfrum et al. 2001). The fact that liver PPAR receptors bind FABP (Rolf et al. 1995) and that FABP can modulate PPAR function in the nucleus by affecting the transport of PPAR ligands into the nucleus (Wolfrum et al. 2001) led us to test the possibility that PPAR- $\alpha$ activation may in turn affect circulating levels of FABP. Our results show that this is not the case and that 3 months of treatment with PPAR- $\alpha$ agonist fenofibrate had no effect on circulating FABP levels despite its ability to significantly decrease circulating triglycerides and free fatty acids.

However, our study has revealed other interesting relationships between circulating FABP levels and metabolic parameters. First, we have documented a very close positive correlation not only between FABP levels and the degree of obesity as measured by BMI but also even stronger positive correlation between FABP and blood glucose or glycated hemoglobin, respectively. Second, our study is the first one to demonstrate a strong inverse relationship between FABP levels and parameters of insulin sensitivity as measured by hyperinsulinemicisoglycemic clamp. Our data suggest that circulating FABP levels are directly regulated by insulin as documented by suppression of FABP concentrations during hyperinsulinemic-isoglycemic clamp. Interestingly, the degree of suppression was significantly greater in untreated patients with type 2 diabetes relative to healthy controls suggesting that insulin deficiency and/or insulin resistance may be involved in the increase of FABP levels in type 2 diabetic patients.

Several adipocyte-derived factors have been originally described as important players in the development of insulin resistance and type 2 diabetes mellitus while later studies have shown that they are rather the markers of ongoing metabolic disturbances than its primary cause (Hotamisligil et al. 1993, Steppan et al. 2001). Since there are at present only few studies focused on the significance of circulating FABP levels in the development of insulin resistance in humans and none of them is a prospective one, it is currently unclear whether circulating FABP is only a marker or an active player in this process. Furthemore, it should be noted that not only adipocytes but also immunocompetent cells such as macrophages might be an important source of circulating FABP (Makowski et al. 2005). Nevertheless, it is safe to conclude that FABP is one of the factors most closely related to BMI, diabetes compensation and insulin sensitivity from the wide scale of adipose tissue-derived hormones including the most commonly studied ones such as adiponectin and resistin (Anderlová et al. 2006, McTernan et al. 2002, Weyer et al. 2001).

In summary, our study has documented that circulating FABP levels are strongly related to several features of insulin resistance syndrome. It remains to be determined whether circulating FABP is only the strong marker of ongoing metabolic disturbances or one of its primary causes.

\section{Conflict of Interest}

There is no conflict of interest.

\section{Acknowledgements}

Supported by Research Project of MHCR MZO VFN 2005 and grant of IGA MHCR No. 8302-5.

\section{References}

ANDERLOVÁ K, KŘEMEN J, DOLEŽALOVÁ R, HOUSOVÁ J, HALUZÍKOVÁ D, KUNEŠOVÁ M, HALUZÍK M: The influence of very-low-calorie-diet on serum leptin, soluble leptin receptor, adiponectin and resistin levels in obese women. Physiol Res 55: 277-283, 2006. 
BINAS B, DANNEBERG H, MCWHIR J, MULLINS L, CLARK AJ: Requirement for the heart-type fatty acid binding protein in cardiac fatty acid utilization. FASEB $J$ 13: 805-812, 1999.

BOORD JB, FAZIO S, LINTON MF: Cytoplasmic fatty acid-binding proteins: emerging roles in metabolism and atherosclerosis. Curr Opin Lipidol 13: 141-147, 2002.

DEFRONZO RA, TOBIN JD, ANDRES R: Glucose clamp technique: a method for quantifying insulin secretion and resistance. Am J Physiol 237: E214-E123, 1979.

GUERRE-MILLO M, GERVOIS P, RASPE E, MADSEN L, POULAIN P, DERUDAS B, HERBERT JM, WINEGAR DA, WILLSON TM, FRUCHART JC, BERGE RK, STAELS B: Peroxisome proliferator-activated receptor alpha activators improve insulin sensitivity and reduce adiposity. $J$ Biol Chem 275: 16638-42, 2000.

HAFFNER SM: Pre-diabetes, insulin resistance, inflammation and CVD risk. Diabetes Res Clin Pract 61 (Suppl 1): S9S18, 2003.

HAFFNER SM, LEHTO S, RONNEMAA T, PYORALA K, LAAKSO M: Mortality from coronary heart disease in subjects with type 2 diabetes and in nondiabetic subjects with and without prior myocardial infarction. $N E n g l$ J Med 339: 229-234, 1998.

HALUZÍK M, PAŘIIZKOVÁ J, HALUZÍK MM: Adiponectin and its role in the obesity-induced insulin resistance and related complications. Physiol Res 53: 123-129, 2004.

HALUZÍK MM, HALUZÍK M: PPAR-alpha and insulin sensitivity. Physiol Res 55: 115-122, 2006.

HALUZÍK MM, LACINOVÁ Z, DOLÍNKOVÁ M, HALUZÍKOVÁ D, HOUSA D, HOŘÍNEK A, VERNEROVÁ Z, KUMŠTÝŘOVÁ T, HALUZÍK M: Improvement of insulin sensitivity after peroxisome proliferator-activated receptor-alpha agonist treatment is accompanied by paradoxical increase of circulating resistin levels. Endocrinology 147: 4517-4524, 2006.

HAVEL PJ: Control of energy homeostasis and insulin action by adipocyte hormones: leptin, acylation stimulating protein, and adiponectin. Curr Opin Lipidol 13: 51-59, 2002.

HOTAMISLIGIL GS, SHARGILL NS, SPIEGELMAN BM: Adipose expression of tumor necrosis factor-alpha: direct role in obesity-linked insulin resistance. Science 259: 87-91, 1993.

HOUSA D, HOUSOVÁ J, VERNEROVÁ Z, HALUZÍK M: Adipocytokines and cancer. Physiol Res 55: 233-244, 2006.

HOUSOVÁ J, WILCZEK H, HALUZÍK MM, KŘEMEN J, KŘÍZOVÁ J, HALUZÍK M: Adipocyte-derived hormones in heroin addicts: the influence of methadone maintenance treatment. Physiol Res 54: 73-78, 2005.

KARPÍŠEK M, STEJSKAL D, KOTOLOVÁ H, KOLLAR P, JANOUTOVÁ G, OCHMANOVÁ R, ČíŽEK L, HORÁKOVÁ D, YAHIA RB, LICHNOVSKÁ R, JANOUT V: Treatment with atorvastatin reduces serum adipocyte-fatty acid binding protein value in patients with hyperlipidaemia. Eur J Clin Invest 37: 637-462, 2007.

LEVY E, MENARD D, DELVIN E, STAN S, MITCHELL G, LAMBERT M, ZIV E, FEOLI-FONSECA JC, SEIDMAN E: The polymorphism at codon 54 of the FABP2 gene increases fat absorption in human intestinal explants. J Biol Chem 276: 39679396-84, 2001.

MAKOWSKI L, BRITTINGHAM KC, REYNOLDS JM, SUTTLES J, HOTAMISLIGIL GS: The fatty acid-binding protein, aP2, coordinates macrophage cholesterol trafficking and inflammatory activity. Macrophage expression of aP2 impacts peroxisome proliferator-activated receptor gamma and IкB kinase activities. $J$ Biol Chem 280: 12888-12895, 2005.

MCTERNAN CL, MCTERNAN PG, HARTE AL, LEVICK PL, BARNETT AH, KUMAR S: Resistin, central obesity, and type 2 diabetes. Lancet 359: 46-47, 2002.

REAVEN GM: Role of insulin resistance in human disease. Diabetes 37: 1595-607, 1988.

REAVEN GM: Syndrome X. Blood Press Suppl 4: 13-16, 1992.

ROLF B, OUDENAMPSEN-KRUGER E, BORCHERS T, FAERGEMAN NJ, KNUDSEN J, LEZIUS A, SPENER F: Analysis of the ligand binding properties of recombinant bovine liver-type fatty acid binding protein. Biochim Biophys Acta 1259: 245-253, 1995.

SHULMAN GI: Cellular mechanisms of insulin resistance. J Clin Invest 106: 171-176, 2000. 
STAELS B, KOENIG W, HABIB A, MERVAL R, LEBRET M, TORRA IP, DELERIVE P, FADEL A, CHINETTI G, FRUCHART JC, NAJIB J, MACLOUF J, TEDGUI A: Activation of human aortic smooth-muscle cells is inhibited by PPARalpha but not by PPARgamma activators. Nature 393:790-3, 1998.

STEJSKAL D, KARPÍŠEK M: Adipocyte fatty acid binding protein in a Caucasian population: a new marker of metabolic syndrome? Eur J Clin Invest 36: 62162-5, 2006.

STEPPAN CM, BAILEY ST, BHAT S, BROWN EJ, BANERJEE RR, WRIGHT CM, PATEL HR, AHIMA RS, LAZAR MA: The hormone resistin links obesity to diabetes. Nature 409: 307-312, 2001.

WEYER C, FUNAHASHI T, TANAKA S, HOTTA K, MATSUZAWA Y, PRATLEY RE, TATARANNI PA: Hypoadiponectinemia in obesity and type 2 diabetes: close association with insulin resistance and hyperinsulinemia. J Clin Endocrinol Metab 86: 1930-1935, 2001.

WOLFRUM C, BORRMANN CM, BORCHERS T, SPENER F: Fatty acids and hypolipidemic drugs regulate peroxisome proliferator-activated receptors alpha- and gamma-mediated gene expression via liver fatty acid binding protein: a signaling path to the nucleus. Proc Natl Acad Sci USA 98: 2323232-8, 2001.

XU A, TSO AW, CHEUNG BM, WANG Y, WAT NM, FONG CH, YEUNG DC, JANUS ED, SHAM PC, LAM KS: Circulating adipocyte-fatty acid binding protein levels predict the development of the metabolic syndrome: a 5year prospective study. Circulation 115: 1537-1543, 2007.

XU A, WANG Y, XU JY, STEJSKAL D, TAM S, ZHANG J, WAT NM, WONG WK, LAM KS: Adipocyte fatty acidbinding protein is a plasma biomarker closely associated with obesity and metabolic syndrome. Clin Chem $\mathbf{5 2}$ : 405-413, 2006.

YONG QW, THAVINTHARAN S, CHENG A, CHEW LS: The effect of fenofibrate on insulin sensitivity and plasma lipid profile in non-diabetic males with low high density lipoprotein/dyslipidaemic syndrome. Ann Acad Med Singapore 28: 778-782, 1999. 